\title{
Thermal Cycle Tests of CLCC Solder Joints: Influence of Substrate, Solder, and Pad Patterns
}

\author{
By Seisuke FuKudA, ${ }^{1)}$ Takayuki IshidA, ${ }^{1)}$ Tetsuhito ARAKAwA, ${ }^{1)}$ \\ Tsuyoshi NAKAGAWA, ${ }^{2)}$ and Hajime MURAO ${ }^{3)}$ \\ ${ }^{1)}$ Institute of Space and Astronautical Science, JAXA, Sagamihara, Japan \\ ${ }^{2)}$ Safety and Mission Assurance Department, JAXA, Tsukuba, Japan \\ ${ }^{3)}$ Meisei Electric Co., Ltd., Isesaki, Japan
}

(Received June 27th, 2019)

\begin{abstract}
SLIM (Smart Lander for Investigating Moon) of ISAS/JAXA is a demonstration mission of lunar pinpoint landing technology with a small spacecraft. The navigation cameras of SLIM require the function of the so-called global shutter in order to take lunar surface images under high orbital velocity. Since the requirement of miniaturization is also critical, we decide to use the commercial CMOS image sensor for the SLIM cameras. The package of the selected CMOS image sensor is the 48-pin CLCC (Ceramic Leadless Chip Carrier). It is known that there are some matters of concerns about reliability of the CLCC solder joints when applied to space missions. So the detailed results of thermal cycle tests for the CLCC packages soldered on the substrates are described in this paper. Several counterplans to improve the robustness of the solder joints are investigated from the substrates and the solders to the pad pattern. From the results of the thermal cycles tests, it is confirmed that the most promising approach to solder the CLCC packages without the significant cracks is to select adequate substrate materials with coefficients of thermal expansion similar to the ceramic.
\end{abstract}

Key Words: CLCC (Ceramic Leadless Chip Carrier), Solder Joint, Thermal Cycle Test

\section{Nomenclature}

$\begin{array}{cll}A & : & \text { cross section, } \mathrm{m}^{2} \\ E & : & \text { Young's modulus, } \mathrm{Pa} \\ G & : & \text { shear modulus, } \mathrm{Pa} \\ H & : & \text { height, } \mathrm{m} \\ L & : & \text { length, } \mathrm{m} \\ \Delta T & : & \text { temperature difference, } \mathrm{K} \\ \alpha & : & \text { coefficients of thermal expansion, } / \mathrm{K} \\ \sigma & : & \text { shear stress, } \mathrm{Pa} \\ \text { Subscripts } & & \\ \text { cer } & : & \text { ceramic } \\ \text { sol } & : & \text { solder } \\ \text { sub } & : & \text { substrate }\end{array}$

\section{Introduction}

Commercial electric parts with advanced functions are sometimes employed in space missions, especially exploration spacecrafts whose resources are severely restricted. SLIM (Smart Lander for Investigating Moon) of ISAS/JAXA is a demonstration mission of lunar pinpoint landing technology with a small spacecraft. ${ }^{1)}$ The navigation cameras of SLIM (hereinafter, referred to as SLIM-CAM) require the function of the so-called global shutter in order to take lunar surface images under high orbital velocity. Since the requirement of miniaturization is also critical, we decide to use the commercial CMOS image sensor for the SLIM-CAMs by executing appropriate screening tests and by confirming radiation tolerance. As most of recent commercial parts are surface mount devices, the package of the selected CMOS image sensor is the 48-pin CLCC (Ceramic Leadless Chip Carrier). It is known that there are some matters of concerns about reliability of the CLCC solder joints when applied to space missions. ${ }^{2), 3)}$ So the detailed results of thermal cycle tests for the CLCC packages soldered on the substrates are described in this paper. The understanding acquired in this study is very instructive to use the CLCC packages for the space applications.

In the following section, after introducing the specification of the SLIM-CAM, the results of the initial thermal cycle tests are shown. In Section 3, several counterplans against the results of the initial tests are considered from materials of the substrates and solders to the pad pattern. The results of retried thermal cycle tests with various solder conditions are described in Section 4. Finally, Section 5 gives conclusions.

\section{Initial Thermal Cycle Test}

\subsection{SLIM-CAM}

SLIM aims at achieving accurate navigation $(\sim 100 \mathrm{~m})$ to the landing point on the moon. The pinpoint landing can bring a paradigm shift in the field of the celestial body landing from 'landing where easy to land' to 'landing where desire to land.' The key technology for the pinpoint landing is the vision-based navigation using crater information. At first, crater extraction from lunar surface images by the SLIM-CAM is executed. ${ }^{4)}$ Subsequently, the current spacecraft location is searched by matching the extracted craters with the crater database prepared before launch. ${ }^{5), 6)}$ 
When SLIM carries out the vision-based navigation, the orbital velocity of SLIM is as high as maximum 1 to $2 \mathrm{~km} / \mathrm{s}$. Therefore, if image sensors with the rolling shutter are used, the obtained images will be distorted as parallelograms. Since such distortion is undesirable for the crater matching, the global shutter became an important functional requirement of the image sensors in the SLIM-CAM. In the space-qualified image sensors, however, there are few candidates with the global shutter. So the commercial CMOS image sensor with the global shutter, e2v Sapphire (EV76C560), ${ }^{7)}$ was employed for the SLIM-CAM on condition that the appropriate screening tests are required. Also the sensor has experienced the on-orbit demonstration by the cubesat mission, ${ }^{8}$ and some data concerning radiation tolerance were acquired through the activity. ${ }^{9)}$

Table 1 shows the specification of the SLIM-CAM, and Fig. 1 is a picture of the SLIM-CAM Engineering Models. In SLIM, two SLIM-CAMs will be loaded. Each SLIM-CAM has the different mechanical interfaces to install on the SLIM structure panel.

\subsection{Initial thermal cycle test of CLCC Solder Joints}

While the SOP (Small Outline Package) and QFP (Quad Flat Package) are conservatively used for the space-qualified electronic parts, the package of the employed CMOS image sensor is the CLCC-type. Figure 2 shows the appearance of the sensor. It is characteristic of the CLCC package that the pins are provided even at the four corners: Three ground lines and one data line.

Since it is recognized that there are some matters of concerns about reliability of the CLCC solder joints due to the difference of thermal expansivity between the substrate and the ceramic package, the mechanical samples soldered on the substrates were submitted to the thermal cycle test. Considering the conditions in the SLIM mission, the range of the thermal cycles was settled as from -30 to $65 \mathrm{degC}$. The gradient of the thermal change was 95 degC per 5 minutes, and the period of the thermal cycles was 70 minutes.

Four mechanical samples of each hand-soldering and reflow-soldering were prepared. Since the residual heat stresses could be reduced, it was expected before the test that the hand-soldering would be more robust against the thermal cycles than the reflow-soldering. In the visual inspections after 50 cycles, however, significant cracks on the solder joints were found on the wide-ranged pins of every four samples by the hand-soldering, though all of the joints by the reflow-soldering survived at this point of time. It is considered that the reasons of the wrong results in the hand-soldering cases are the insufficient solders in the joints; especially the solders under the package could not contribute to the connections probably because the heat of the soldering iron was not conducted adequately.

The number of 200 cycles is more than two MDC (Mission Duty Cycles) of SLIM with enough margins. So again the inspections of the samples by the reflow-soldering were made after 200 cycles. The results revealed that the cracks were generated in the pins around the corners of the package after 200 cycles. Figure 3 (a), (b), and (c) show SEM (Scanning Electron Microscope) images of the sample by the
Table 1. Specification of the SLIM-CAM.

\begin{tabular}{ll}
\hline Field of view & $30 \times 30$ deg \\
Number of pixels & $512 \times 512$ pixels \\
Shutter type & Global shutter \\
Output & Raw (8bit grayscale) \\
& Compressed (JPEG) \\
Data interface & SpaceWire \\
Mass & $530 \mathrm{~g}$ \\
Power & $3.4 \mathrm{~W}$ \\
\hline
\end{tabular}

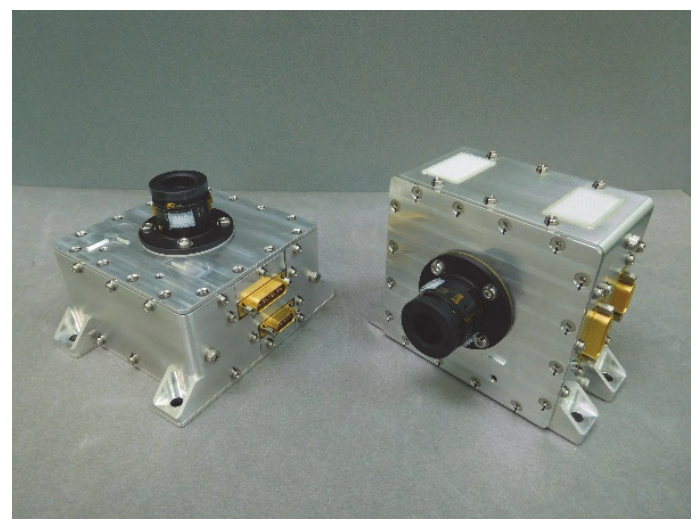

Fig. 1. SLIM-CAM Engineering Models.

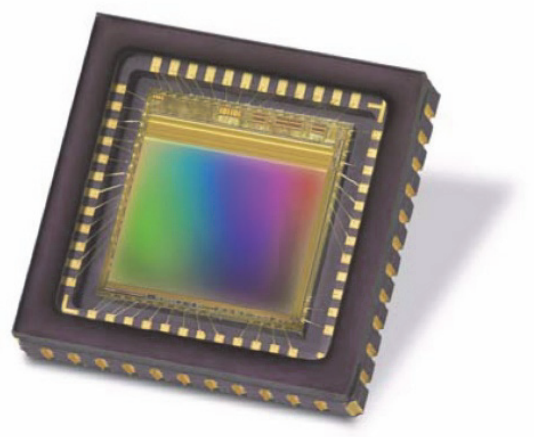

Fig. 2. Appearance of the image sensor with the CLCC package.

reflow-soldering before the test, after 50 cycles, and after 200 cycles, respectively. It can be seen that there are serious cracks at the red circles of Fig. 3(c).

\section{Reconsideration of Soldering Conditions}

Following the results of the initial thermal cycle tests described in Section 2.2, several counterplans were taken into consideration in order to improve the robustness of the CLCC solder joints. By considering the equilibrium of horizontal 


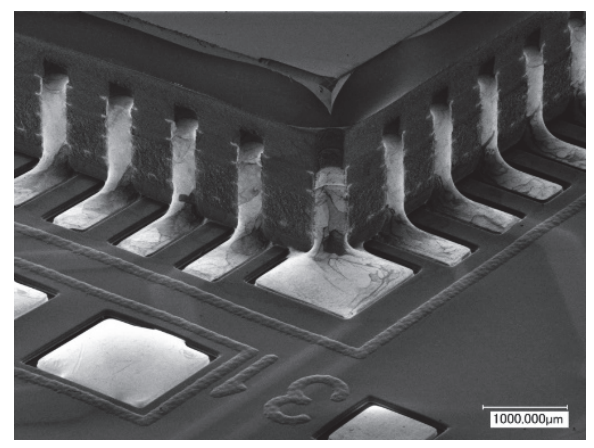

(a)

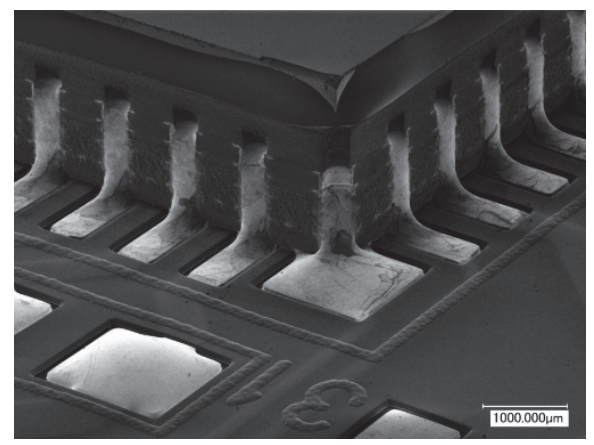

(b)

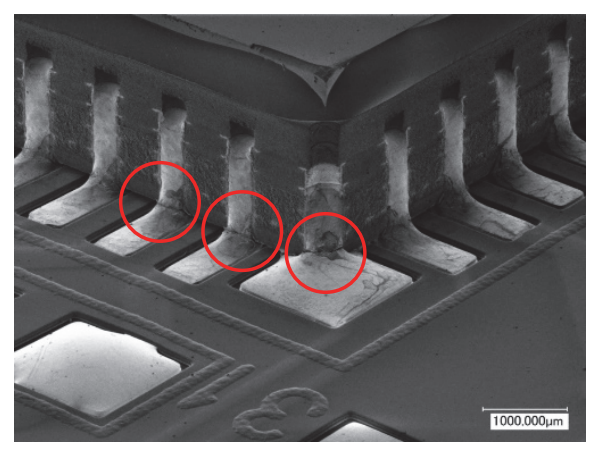

(c)

Fig. 3. SEM images of the sample by the reflow-soldering in the initial thermal cycle tests (a) before the test, (b) after 50 cycles, and (c) after 200 cycles, respectively.

strains simply, the shear stress of the solder is expressed as

$$
\begin{gathered}
\left(\alpha_{c e r} L \Delta T+\frac{L}{A_{c e r} E_{c e r}} F\right)+\left(\alpha_{\text {sol }} L_{\text {sol }} \Delta T+\frac{H_{\text {sol }}}{A_{\text {sol }} G_{\text {sol }}} F\right) \\
=\left(\alpha_{\text {sub }} L \Delta T+\frac{L}{A_{\text {sub }} E_{\text {sub }}} F\right)
\end{gathered}
$$

where $\alpha_{c e r}, \alpha_{\text {sol }}$, and $\alpha_{\text {sub }}$ are the coefficients of thermal expansion of the ceramic, the solder and the substrate, respectively. $L$ is the length of the ceramic and the substrate, and $L_{\text {sol }}$ and $H_{\text {sol }}$ are the length and the height of the solder. $A_{c e r}, A_{\text {sol }}$ and $A_{\text {sub }}$ are the cross section of the ceramic, the solder and the substrate, respectively. $E_{c e r}$ and $E_{s u b}$ are the Young's modulus of the ceramic and the substrate, and $G_{\text {sol }}$ is the shear modulus of the solder. $F$ is the shear force of the solder layer. Considering the length $L_{s o l}$ is negligible, the solder shear stress $\sigma_{\text {sol }}$, which is equal to $F / A_{\text {sol }}$, is expressed as

$\sigma_{\text {sol }}=\left\{\frac{\left(\alpha_{c e r}-\alpha_{s u b}\right) L \Delta T}{\frac{L}{A_{c e r} E_{c e r}}+\frac{H_{s o l}}{A_{s o l} G_{s o l}}+\frac{L}{A_{s u b} E_{s u b}}}\right\} / A_{s o l}$,

where $A_{\text {sol }}$ is the cross section between the solder and the ceramic or the substrate. Hence in the following, the methods for reducing the shear stress of the solder are investigated by reconsidering the soldering conditions, which are substrates, solders, and patterns, in order for the values of the parameters in Eq. (2) to change.

\subsection{Substrates}

The substrate material used in the initial thermal cycle tests is the glass modified polyimide multilayer material. ${ }^{10)}$ The CTE (Coefficients of Thermal Expansion) of the substrate, $\alpha_{\text {sub }}$ is $12-16 \mathrm{ppm} / \mathrm{K}$. The CTE of the ceramic, $\alpha_{c e r}$ is around $7 \mathrm{ppm} / \mathrm{K}$. In order to decrease $\left(\alpha_{c e r}-\alpha_{s u b}\right)$ in Eq. (2), a new substrate material was introduced, which is high $\mathrm{Tg}$ class epoxy multilayer materials with the CTE of 5-7 $\mathrm{ppm} / \mathrm{K}^{11)}$

Cupper leaf was inserted into the substrates of the initial thermal cycle tests as ground planes. It is supposed that the insertion of the cupper leaf increases the Young's modulus of the substrates, $E_{s u b}$, from the value of the material itself. Therefore in order to decrease $E_{\text {sub }}$ in Eq. (2), the cupper ground planes were changed to mesh sheets.

\subsection{Solder}

The composition of the solder is originally $\mathrm{Sn} 63 \mathrm{~Pb} 37$. While the eutectic solder has minute internal structures just after the bonding, it is known that after experience of high temperature or thermal cycles the structures are bloated by the diffusion inside the solder. The occurrence of the cracks is possible to be encouraged by the diffusion especially around the $\mathrm{Pb}$ layer. The bloating of the internal structures, however, can be suppressed by doping chemical elements such as $\mathrm{Sb}$ and $\mathrm{Ag}$ in minuscule quantities. Thus, the eutectic solder composed of $\mathrm{Sn} 62 \mathrm{Sb} 0.5 \mathrm{Ag} 3 \mathrm{~Pb} 34.5$ were newly employed so that the critical value of the solder shear stress $\sigma_{\text {sol }}$ was increased.

The solder paste thickness was $150 \mu \mathrm{m}$ in the initial thermal cycle tests. Since increasing the quantity of the solder by thickening the solder paste brings the effect of controlling $A_{\text {sol }}$ in Eq. (2), the thickness value of $180 \mu \mathrm{m}$ was attempted.

It is expected that the standoff height of the solder $H_{\text {sol }}$ is also related to the breaking out of the cracks. For example, however, doubling $H_{s o l}$ in Eq. (2) seems insensitive to the solder shear stress $\sigma_{\text {sol }}$, probably because the bending stress is not taken into account in Eq. (2). 


\subsection{Patterns}

Concerning the patterns on the substrates, the length of each pad under the package affects the cross section of the solder. Thus, in the revised pattern, every pad is extended by $0.2 \mathrm{~mm}$ toward the bottom of the package. The exceptions are the pads at the corners because they cannot be extended due to the existence of the adjacent pads. Alternatively, the pad of the corner pins is changed to narrower shapes like Fig. 4.

\section{Results of Thermal Cycle Tests with Various Solder Conditions}

According to a variety of conditions described in Section 3, six kinds of samples (i.e., from A150 to B180 in Table 2) were manufactured for the retried thermal cycle tests. In Table $2, \mathrm{Z} 150$ is the samples by the reflow-soldering in the initial thermal cycle test shown in Section 2.2. Of course all of the newly manufactured samples are by way of the reflow-soldering. The revised pattern means that the cupper ground planes are changed to the mesh sheets, and the pad length is extended by $0.2 \mathrm{~mm}$, etc. The sample groups such as $\mathrm{B} 150+$ and $\mathrm{B} 180+$ were not prepared due to the limitation of the number of the CLCC packages; it was expected that the solder joints could become robust against the cracks by

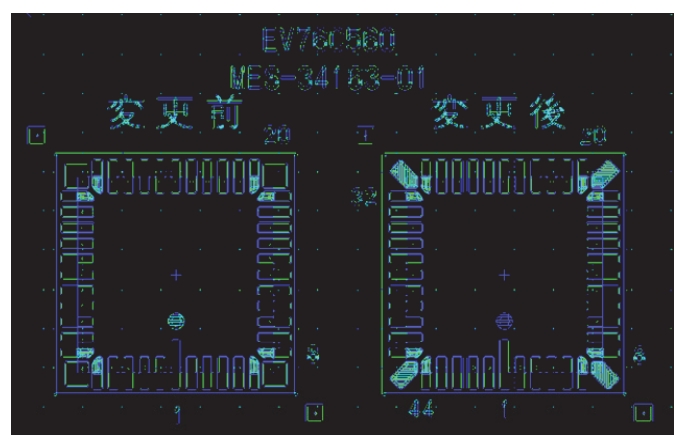

Fig. 4. Pad patterns: (left) original and (right) revised.

changing either the substrate material or the solder composition. For each group, the number of samples is 4, except that $\mathrm{A} 180+$ is 3 samples.

The retried tests were conducted with the same range and period of the thermal cycles as Section 2.2. After 200 cycles, visual inspections with an optical microscope with a magnification of $15 \mathrm{x}$ were done for four corner pins and eight pins next to the corners per a sample. Referring to the JAXA standard about the crack categorization for different

Table 2. Samples for the retried thermal tests. For comparison the samples of the initial test are also shown.

\begin{tabular}{|c|c|c|c|c|c|c|c|c|}
\hline & \multirow{2}{*}{\multicolumn{2}{|c|}{ Substrate material }} & \multicolumn{4}{|c|}{ Solder } & \multirow[b]{3}{*}{ Patterns } & \multirow[b]{3}{*}{$\begin{array}{c}\text { Number of } \\
\text { samples }\end{array}$} \\
\hline & & & \multicolumn{2}{|c|}{ Composition } & \multicolumn{2}{|c|}{ Thickness } & & \\
\hline & $\begin{array}{l}\text { Glass } \\
\text { modified } \\
\text { polyimide } \\
\text { multilayer } \\
\text { material }\end{array}$ & $\begin{array}{l}\text { High Tg } \\
\text { class epoxy } \\
\text { multilayer } \\
\text { material }\end{array}$ & $\mathrm{Sn} 63 \mathrm{~Pb} 37$ & $\begin{array}{l}\text { Sn62Sb0.5 } \\
\text { Ag3Pb34.5 }\end{array}$ & $150 \mu \mathrm{m}$ & $180 \mu \mathrm{m}$ & & \\
\hline $\mathrm{Z} 150$ & $\mathrm{x}$ & & $\mathrm{x}$ & & $\mathrm{x}$ & & original & 4 \\
\hline A150 & $x$ & & $\mathrm{x}$ & & $\mathrm{x}$ & & & 4 \\
\hline A180 & $\mathrm{x}$ & & $\mathrm{x}$ & & & $\mathrm{x}$ & & 4 \\
\hline A150+ & $\mathrm{x}$ & & & $\mathrm{x}$ & $\mathrm{x}$ & & & 4 \\
\hline A180+ & $\mathrm{x}$ & & & $\mathrm{x}$ & & $\mathrm{x}$ & revised & 3 \\
\hline $\mathrm{B} 150$ & & $\mathrm{x}$ & $\mathrm{x}$ & & $\mathrm{x}$ & & & 4 \\
\hline B180 & & $\mathrm{x}$ & $\mathrm{x}$ & & & $\mathrm{x}$ & & 4 \\
\hline
\end{tabular}

Table 3. Results of the visual inspections of the crack occurrence after the retried thermal tests.

\begin{tabular}{|c|c|c|c|c|c|c|c|c|c|c|c|c|c|c|c|c|c|c|}
\hline \multirow{3}{*}{$\begin{array}{l}\text { Sample } \\
\text { Crack } \\
\text { position } \\
\text { Crack } \\
\text { length }\end{array}$} & \multicolumn{4}{|c|}{$\# 1$} & \multicolumn{4}{|c|}{$\# 2$} & \multicolumn{4}{|c|}{$\# 3$} & \multicolumn{4}{|c|}{$\# 4$} & \multirow{2}{*}{\multicolumn{2}{|c|}{ Total }} \\
\hline & \multicolumn{2}{|c|}{ Corners } & \multicolumn{2}{|c|}{$\begin{array}{l}\text { Next to } \\
\text { corners }\end{array}$} & \multicolumn{2}{|c|}{ Corners } & \multicolumn{2}{|c|}{$\begin{array}{l}\text { Next to } \\
\text { corners }\end{array}$} & \multicolumn{2}{|c|}{ Corners } & \multicolumn{2}{|c|}{$\begin{array}{l}\text { Next to } \\
\text { corners } \\
\end{array}$} & \multicolumn{2}{|c|}{ Corners } & \multicolumn{2}{|c|}{$\begin{array}{l}\text { Next to } \\
\text { corners }\end{array}$} & & \\
\hline & $\leq 1 / 2$ & $\geq 1 / 2$ & $\leq 1 / 2$ & $\geq 1 / 2$ & $\leq 1 / 2$ & $\geq 1 / 2$ & $\leq 1 / 2$ & $\geq 1 / 2$ & $\leq 1 / 2$ & $\geq 1 / 2$ & $\leq 1 / 2$ & $\geq 1 / 2$ & $\leq 1 / 2$ & $\geq 1 / 2$ & $\leq 1 / 2$ & $\geq 1 / 2$ & $\leq 1 / 2$ & $\geq 1 / 2$ \\
\hline A 150 & 1 & 3 & 0 & 3 & 4 & 0 & 1 & 1 & 1 & 3 & 2 & 1 & 0 & 4 & 0 & 2 & 9 & 17 \\
\hline A180 & 1 & 3 & 0 & 0 & 1 & 3 & 0 & 1 & 0 & 4 & 1 & 0 & 2 & 1 & 0 & 0 & 5 & 12 \\
\hline $\mathrm{A} 150+$ & 3 & 1 & 0 & 0 & 1 & 3 & 2 & 0 & & & & & 0 & 4 & 2 & 0 & 8 & 8 \\
\hline A180+ & 3 & 1 & 0 & 0 & 1 & 2 & 0 & 0 & & & & & - & - & - & - & 4 & 3 \\
\hline B150 & 2 & 0 & 0 & 0 & 1 & 0 & 0 & 0 & & & & & 3 & 0 & 0 & 0 & 6 & 0 \\
\hline B180 & 1 & 0 & 0 & 0 & 0 & 0 & 0 & 0 & & & & & 1 & 0 & 0 & 0 & 2 & 0 \\
\hline
\end{tabular}



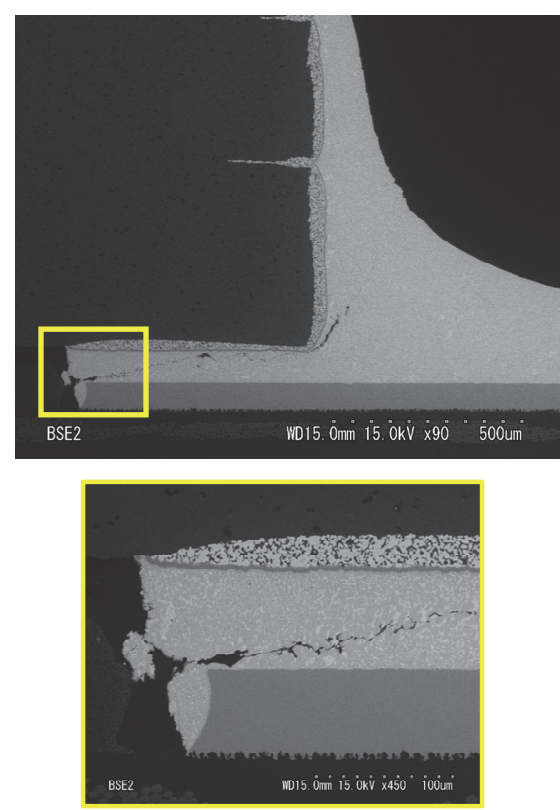

(a)
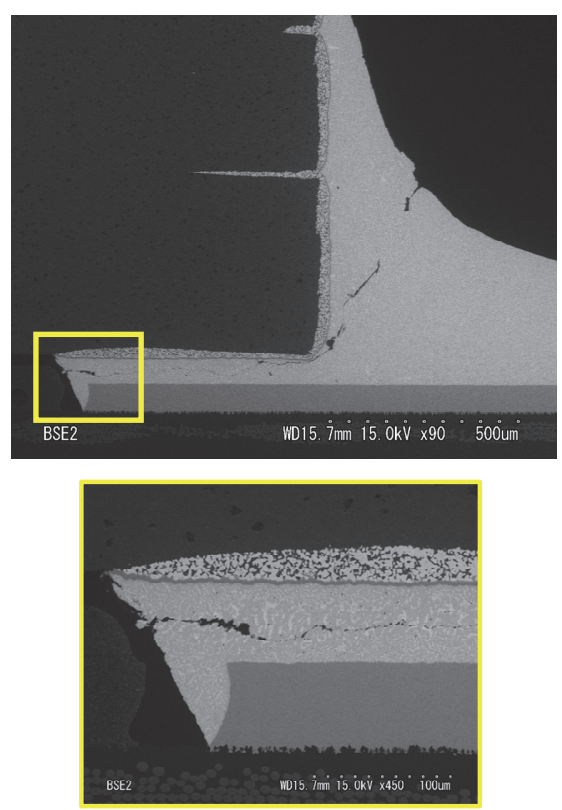

(b)
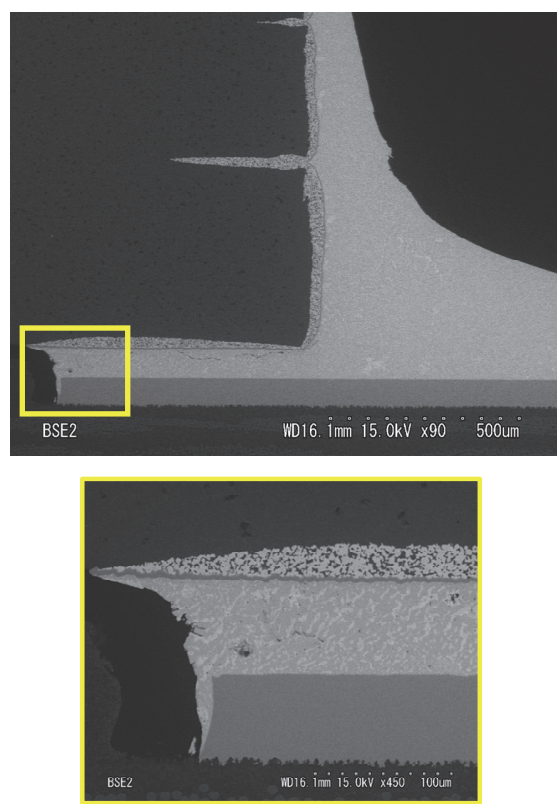

(c)
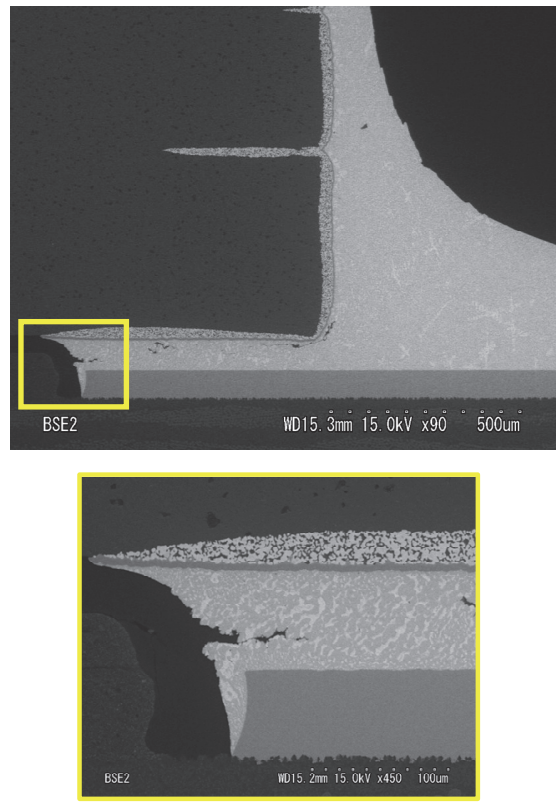

(d)
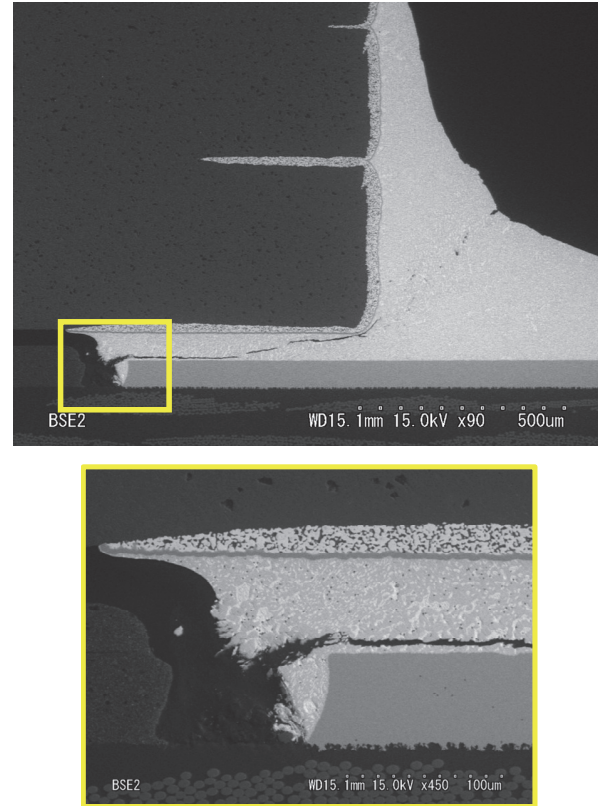

(e)

Fig. 5. SEM images in the cross-sectional observation of (a) A150+, (b) A180+, (c) B150, (d) B180, and (e) Z150, respectively.

packages, ${ }^{12)}$ a criterion for judging was employed, whether the length of cracks was more than half of the terminal width or not.

The results of the visual inspections are summarized in Table 3. As the samples \#3 of A150+, A180+, B150, and B180 were used for the cross-sectional observation by the SEM described in detail below, the inspections by the optical microscope were skipped. From the results in Table 3, it can be said that $\mathrm{A} 150$, in which only patterns were revised from the original Z150, still suffers from the cracks: In 17 pins ( $35 \%$ of inspected pins) the cracks with more than $1 / 2$ length were detected. While it is effective to thicken the solder from 150 to $180 \mu \mathrm{m}$ (e.g., from A150 to A180) or to use the eutectic solder composed of $\mathrm{Sn} 62 \mathrm{Sb} 0.5 \mathrm{Ag} 3 \mathrm{~Pb} 34.5$ (e.g., from $\mathrm{A} 150$ to $\mathrm{A} 150+$ ), these counterplans seemed not enough for exterminating the cracks. On the other hand, no cracks with 
more than $1 / 2$ length were detected in the samples with the substrates using the high Tg class epoxy multilayer materials (i.e., B150 and B180). The results indicate that the most promising approach to solder the CLCC packages without the significant cracks after the thermal cycles is to select the adequate substrate materials with the CTE similar to the ceramic.

Figure 5 (a) to (d) show the SEM images in the cross-sectional observation of $\mathrm{A} 150+, \mathrm{A} 180+, \mathrm{B} 150$, and $\mathrm{B} 180$, respectively. The same positions of the corner pin (No.7) were observed. Though relatively long cracks are found in Fig. 5 (a) and (b), there are little cracks in Fig. 5 (c) and (d) which are the results of the samples with the substrates using the high $\mathrm{Tg}$ class epoxy multilayer materials. Nevertheless, the cracks in Fig. 5 (a) and (b) do not fully divide the solder joints, so that electrical connection would be retained. For comparison, the observation result of Z150 (No.31 pin), which is the sample of the initial test, is shown in Fig. 5 (e). Even in this image, it cannot be seen that the cracks fully divide the solder joint.

\section{Conclusion}

The commercial CMOS image sensor with the CLCC package is employed for the SLIM-CAM. Since there are some matters of concerns about reliability of the CLCC solder joints when applied to the space missions, the detailed results of thermal cycle tests for the CLCC packages soldered on the substrates were described in this paper. Several counterplans to improve the robustness of the solder joints were investigated from the substrates and the solders to the pad pattern. From the results of the thermal cycle tests, it was confirmed that the most promising approach to solder the CLCC packages without the significant cracks was to select the adequate substrate materials with the CTE similar to the ceramic. The results shown in this paper is very informative for the space use of the CLCC-like packages.

\section{Acknowledgments}

The authors would like to thank Mr. Koichi Suzuki, Mr. Norio Nemoto, and Mr. Shunji Sano of JAXA for providing helpful suggestions in the thermal cycle tests.

\section{References}

1) Sawai, S., Fukuda, S., Sakai, S., Kushiki, K., Arakawa, T., Sato, E., Tomiki, A., Michigami, K., Kawano, T., Okazaki, S., Kukita, A., Miyazawa, Y., Ueda, S., Tobe, H., Maru, Y., Shimoji, H., Shimizu, Y., Shibasaki, Y., Shimada, S., Yokoi, T., Yabushita, T., Sato, K., Nakamura, K., Kuhara, T., Takami, T., Tanaka, N., and Furukawa, K.: Preliminary System Design of Small Lunar Landing Demonstrator SLIM, Aerospace Technology Japan, 17 (2018), pp. 35-43 (in Japanese).

2) Wen, L., and Ross, Jr., R., G.: Comparison of LCC Solder Joint Life Predictions with Experimental Data, J. Electronic Packaging, 117 (1995), pp. 109-115.

3) Burchett, S. N.: Stress Analysis of a Leadless Chip Carrier Soldered to a Ceramic Substrate, Sandia National Laboratories, SAND-90-0750C, 1991.

4) Takino, T., Nomura, I., Irie, J., Nagata, S., Kamata, H., Takadama, K., Fukuda, S., Sawai, S., and Sakai, S.: Crater Detection Method Using Principle Component Analysis And Its Evaluation, Trans. JSASS Aerospace Tech. Japan, 14, ists30 (2016), pp. Pt_7-Pt_14.

5) Kariya, K., Ishida, T., Sawai, S., Kinoshita, T, Kajihara, K., Iwasa, O., and Fukuda, S.: Position Estimation Using Crater-based Linear Features for Pinpoint Lunar Landing, Aerospace Technology Japan, 17 (2018), pp. 79-87 (in Japanese).

6) Ishii, H., Murata, A., Uwano, F., Tatsumi, T., Umenai, Y., Takadama, K., Harada, T., Kamata, H., Ishida, T., Fukuda, S., Sawai, S., and Sakai, S.: SLIM Spacecraft Location Estimation by Crater Matching Based on Similar Triangles and Its Improvement, Aerospace Technology Japan, 17 (2018), pp. 69-78 (in Japanese).

7) EV76C560 Datasheet, 1005B-IMAGE-11/10/11, e2v, 2011, https:/www.teledyne-e2v.com/content/uploads/2014/02/DSC_EV7 6C560.pdf (accessed April 11, 2019).

8) Holland, A., Burgon, R., Harriss, R., and Holland, K.: C3D - An Imaging Radiation Damage Experiment on UKUBE-1, 4S Symposium 2014, Majorca, Spain, 2014.

9) Rushton, J., E., Stefanov, K., D., Holland, A., D., Bugnet, H., Mayer, F., Cordrey-Gale, M., and Endicott, J.: Single Event Effects in $0.18 \mathrm{~m}$ CMOS Image Sensors, SPIE Astronomical Telescopes + Instrumentation, Edinburgh, Scotland, UK, 99152Q, 2016.

10) MCL-I-671 Datasheet, Hitachi Chemical, http://www.hitachi-chem.co.jp/english/products/bm/files/mcl_i_67 1.pdf (accessed April 11, 2019)

11) MCL-E-705G Datasheet, Hitachi Chemical, http://www.hitachi-chem.co.jp/english/products/bm/files/mcl_e_70 5g.pdf (accessed April 11, 2019)

12) Japan Aerospace Exploration Agency: Soldering Process Standard of Space-use Surface Mount, JERG-0-043C, pp.42, 2016. 